\title{
Resin-impregnated Wooden Anti-glare Board and Its Outstanding Exterior Performance
}

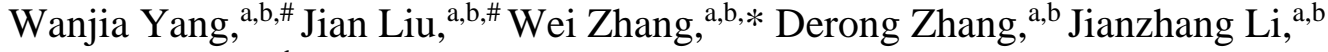 \\ Shifeng Zhang, ${ }^{\mathrm{a}, \mathrm{b}}$ and Yanming Han ${ }^{\mathrm{c}}$
}

\begin{abstract}
A large amount of plant waste from the sides of highways is trimmed and burned, which causes environmental pollution. In addition, headlight glare that occurs when two cars pass each other is dangerous. Traditional antiglare boards are mostly made of metal, plastic, and other materials that easily age and are expensive to recycle. To recycle the plant waste and prevent glare-related accidents, in the present study, a painted wooden anti-glare board (WAB) was developed and its performance was investigated. In the WAB, there are 7 layers of eucalyptus veneers interlaced, and the mechanical strength of the board prepared with a gradient hot-pressing process after impregnation with phenolic resin was good $(79.8 \mathrm{MPa})$. The wind load resistance of the WAB reached $864 \mathrm{~N}$, which meets GB/T 24718 (2009) and is close to that of glass fiberreinforced plastic anti-glare boards $(914 \mathrm{~N})$. After 10 cycles of weather resistance tests comprising submersion, freezing, and hot-drying, the average static bending strength of the WAB was $29.6 \mathrm{~N} / \mathrm{mm}^{2}$. The limited oxygen index of the WAB was $26.1 \%$. Therefore, the WAB showed good properties. The implemented research strategy broadens the application range of the wood composite material and endows it with high added value.
\end{abstract}

Keywords: Highway; Plant waste; Glare, Wooden anti-glare board; Phenolic resin

Contact information: a: Key Laboratory of Wood-Based Materials Science and Utilization, Beijing Forestry University, No. 35 Tsinghua East Road, Haidian District, Beijing 100083, China; b: Beijing Key Laboratory of Wood Science and Engineering, Beijing Forestry University, No. 35 Tsinghua East Road, Haidian District, Beijing 100083, China; c: Research Institute of Forestry New Technology, Chinese Academy of Forestry, Xiangshan Road, Beijing 100091, China; ${ }^{\#}$ The first two authors contributed to this work equally

*Corresponding author: zhangwei@bjfu.edu.cn

\section{INTRODUCTION}

On both sides of highways around the world, a wide range of tall, fast-growing timber species, such as eucalyptus, poplar, and pine, have been extensively planted in large quantities in consideration of aesthetics, wind protection, and water and soil conservation. With the rapid development of highway construction, the amount of green waste, including trunks, branches, and leaves, on the sides of highways is rapidly increasing. Moreover, because priority is given to tree species with fast-growing wood, an enormous amount of trimmed branches is disposed via incineration or landfilling, which causes poor biomass resource utilization, and even fire and smoke that can easily cause secondary disasters. Therefore, the traditional plant waste treatment methods, such as incineration and landfilling, cannot meet the requirements of sustainable development, and the environmentally friendly and high-value-added utilization of plant waste is becoming an inevitable trend (Bai et al. 2010). 
Low biomass resource utilization is not the only problem on the highway. There also is a problem of traffic accidents caused by glare phenomena. Glare is one of the main causes of traffic accidents on two-way highways. At night, the brightness of oncoming headlights changes substantially in an instant, thereby instantly decreasing the visual function of drivers and producing an uncomfortable light sense, which affects normal driving and can ultimately lead to traffic accidents (Zhang 2008) Traffic accidents caused by glare account for $12 \%$ to $15 \%$ of total traffic accidents (Tu et al. 2004), and anti-glare devices, such as fixed barriers (Bagui and Ghosh 2012) or plastic anti-glare devices (Tollazzi and Rencelj 2012), are therefore usually installed in the middle of two-way lanes. As an economic benefit, these devices also reduce the deceleration demand of vehicles, thereby reducing their running cost (Tian et al. 2014; Cherubini et al. 2019).

As an anti-glare device, anti-glare boards are a row of boards attached to the highway's central isolation belt, each of which is about one meter high. They are installed on a metal fixed base and splint, such that every two boards are 1 to 1.5 meters apart. At low speeds, the driver can see through the gap between the anti-glare boards, enabling them to view what is going on in the opposite lane on the other side of the central isolation belt. But for the reason that straight lanes on the highway do not allow cars to travel in opposite directions in the same lane, a central barrier has been created that cannot be crossed. Therefore, it is not necessary to look at the opposite lane when the vehicle is driving at high speed, and the anti-glare boards in the driver's line of sight forms a visual opaque wall due to the high speed and direction of viewing. So, the anti-glare boards can avoid the phenomenon that the driver's visual function being suddenly reduced due to the sudden change of the opposite headlights.

The necessity of anti-glare devices for highway traffic safety has been recognized. Fernandes (2005) revealed the causes of glare and its threat to traffic safety. It was shown that anti-glare boards are an important means by which to solve the problem of glare on highways (Tian et al. 2014). The existing anti-glare devices utilized on highways can be divided into three categories, namely green fences, anti-glare nets, and anti-glare boards. Green fence anti-glare strategies refer to the planting of plants in the central area of the highway; plants have a good anti-glare effect and improve the landscape view, but the necessary investment is high. Moreover, because they are easily affected by the climate, they require long-term maintenance (Han et al. 2018). An anti-glare net is a reticular metal isolation layer covered with anti-rust paint and good ventilation; however, its anti-glare effect is poor and it can easily be affected by snow cover (Yi et al. 2016). Anti-glare boards are the main anti-glare measures implemented on highways due to their good shading, relatively small investment, low maintenance costs, aesthetics, and robustness to snow cover, among other factors. The existing anti-glare boards used on highways can be divided into three types, namely steel, plastic, and glass fiber-reinforced plastic (FRP) boards. Steel anti-glare boards are difficult to maintain, easily expanded by heat, and can easily fall off their base. In the event of a traffic accident, there is a great possibility of secondary injury resulting from the rupture of a steel anti-glare board, which increases the safety hazard of vehicles and personnel (Yi et al. 2016). Plastic anti-glare boards are primarily made of high-density polyethylene (HDPE), polyvinyl chloride (PVC), or acrylonitrile butadiene styrene (ABS) material, and can be made to look aesthetically pleasing. However, their temperature and weather resistance are poor, and these boards easily age and change color. In cold areas often subjected to low-temperature conditions, the material gets brittle and fragile; in contrast, in hot areas, the material softens. The FRP anti-glare boards are primarily made of glass fiber and epoxy resin. Due to its light weight, high strength, and 
corrosion, aging, and high-temperature resistance, FRP has become the most important material for anti-glare boards (Liang 2012; Li 2014). The FRP anti-glare plate is molded, it is a material that has an anisotropic characteristic, and the internal and external material is the same. However, FRP anti-glare boards greatly increase highway maintenance and operation costs, as they are expensive and difficult to recycle after aging.

A novel wooden anti-glare board (WAB) was developed in this study. In this new type of wood composite material, eucalyptus veneers are used as the wood substrate, which is made with trimmed eucalyptus branches, and the trimmed eucalyptus branches are sliced into eucalyptus veneers by a peeling machine. This substrate is efficiently filled with highperformance phenolic resin and is then solidified and formed under a certain temperature and pressure via the penetration of the small molecules of the resin into the wood pores. The weight ratio of the pre-impregnated wood veneer to the post-impregnated wood veneer is 1:1.3 1.4, which means that approximately $30 \%$ of the phenolic resin is soaked into the wood veneer. Phenolic resin is a highly crosslinked adhesive with excellent properties, such as a high bonding strength, acid and alkali corrosion resistance, ideal hardness, thermal stability, and water resistance, and is widely used in the preparation of plywood, particle board, oriented strand board (OSB), and other man-made boards (Aziz et al. 2019). According to previous studies, the static bending modulus of phenolic plywood is around 74.08 $\mathrm{MPa}$ when the hot-pressing pressure is $2.5 \mathrm{MPa}$ (Wu 2012).

However, in contrast to ordinary decorative or building formwork phenolic plywood, anti-glare boards are used in outdoor environments. Highways and other outdoor environments are characterized by harsh conditions, including high and low temperatures, as well as occasional high humidity, high salinity, high light radiation, and high wind speeds. Under these conditions, ordinary wood-based panels are prone to corrosion, breaking, and aging, so anti-glare boards must have good weather resistance and mechanical properties. The impregnation of wood with phenolic resin can effectively prevent the biological degradation of the wood caused by rot fungus, improve the mechanical properties of the wood, and greatly improve the weather resistance, dimensional stability, strength, and other properties of the wood (Furuno et al. 2004; Hermawan et al. 2013).

The wood fiber of the proposed phenolic resin-impregnated WAB has good toughness, which can ensure that the WAB will not break easily when it is impacted by a high-strength external force. Additionally, the crosslinked network structure formed by the phenolic resin after curing has extremely strong rigidity, which can reduce the swinging range of the WAB under a strong wind load, improve the WAB's anti-fatigue strength, and meet the strict practical requirements, such as functionality in high-temperature, highsalinity, and high-humidity environments (Shams et al. 2004). Therefore, the mechanical strength, weather resistance, aging resistance, and other performance indexes of wood composites modified with phenolic resin can meet the GB/T 24718 (2009) requirements and the actual use requirements of anti-glare boards (Yi et al. 2016).

The proposed phenolic resin-impregnated WAB also has the advantages of an excellent performance, low cost of raw materials, and the use of renewable raw materials and waste, and it has prospects in terms of economic value. Due to its higher mechanical strength, toughness, and stronger aging resistance, the proposed phenolic resinimpregnated $\mathrm{WAB}$ has a longer service life and can reduce highway maintenance costs. The service life of a plastic anti-glare board is generally two years, while that of an FRP anti-glare board is three to five years (Yi et al. 2016); in contrast, the design service life of the proposed WAB is more than five years. In addition, through the comparison of factory 
cost price, the cost price of eucalyptus anti-glare board is the lowest, while the cost price of glass fiber-reinforced plastic (FRP) board is 3 times that of wood composite material. Therefore, wood anti-glare board have a certain advantage in the cost price (Guan et al. 2016). The research and development of green, renewable, and low-cost anti-glare boards have important practical significance for the realization of the low-carbon, safe, and sustainable development of expressways.

\section{EXPERIMENTAL}

\section{Materials}

The materials used in this study included phenol, formaldehyde (37\%), and sodium hydroxide (40\%) (Beijing Lan-yi Chemical Product Limited Liability Company, Beijing, China). The size of the veneer used in the laboratory experiment was $0.4 \mathrm{~m} \times 0.4 \mathrm{~m}$, while the size of the veneer used in the factory experiment was $1.2 \mathrm{~m} \times 0.8 \mathrm{~m}$. Other materials included 1-mm-thick poplar veneer (PV), 1.2-mm-thick eucalyptus veneer (EV), and 0.5mm-thick birch veneer (BV) with veneer moisture contents of 8\% to 10\% (Shandong Qiansen Wood Group Co., Ltd., Shandong, China).

\section{Preparation of phenolic resin}

(1) Phenol was added to a reactor, after which water and the first batch of sodium hydroxide solution $(40 \%)$ were added under stirring.

(2) The first batch of formaldehyde (37\%) was slowly added, and the temperature was increased to $80{ }^{\circ} \mathrm{C}$ for 20 to $30 \mathrm{~min}$. Heating was then stopped, and the temperature of the reaction solution was increased to above $90{ }^{\circ} \mathrm{C}$ via an exothermic reaction. The temperature was then maintained at 90 to $95^{\circ} \mathrm{C}$ for 30 to $50 \mathrm{~min}$.

(3) The temperature was reduced to $80^{\circ} \mathrm{C}$, and the second batches of formaldehyde (37\%) and the sodium hydroxide solution (40\%) were slowly added to the reactor. The temperature was then increased to $90{ }^{\circ} \mathrm{C}$ and maintained at 90 to $95{ }^{\circ} \mathrm{C}$ for 15 to $30 \mathrm{~min}$.

(4) The viscosity was measured with a Grignard tube. When the viscosity of the glue reached 200 to $250 \mathrm{mPas}\left(40^{\circ} \mathrm{C}\right)$, the temperature was immediately lowered to $40^{\circ} \mathrm{C}$, and the material was discharged.

\section{Preparation of WAB}

$W A B$ prepared in the laboratory

High-performance phenolic resin was used to efficiently impregnate the wood substrate. After the small molecules of the phenolic resin penetrated the wood pores, the resin was solidified and formed under a certain temperature and pressure.

The veneer treatment was as follows. The wood veneer was soaked in phenolic resin for $2 \mathrm{~h}$, after which it was removed and the residual liquid was drained from the surface. The veneer was then dried in an air-blast drying oven at $60{ }^{\circ} \mathrm{C}$ for $1 \mathrm{~h}$, after which it was removed and dried at room temperature.

The veneer arrangement was as follows. Seven pieces of veneer were placed in accordance with an alternating arrangement or a unidirectional arrangement. Copper mesh and iron gauze were added to the veneer with an alternating arrangement. Hot-pressing was conducted as follows. A gradient hot-pressing process was adopted, and the hot-pressing temperature was maintained at 120 to $150{ }^{\circ} \mathrm{C}$. The hot-pressing time of the first stage was 500 to $600 \mathrm{~s}$, and the hot-pressing pressure was $1.2 \mathrm{MPa}$. 

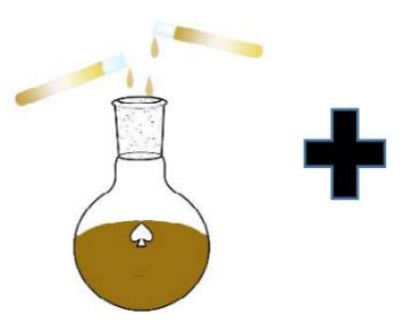

Synthetic phenolic resin for impregnation

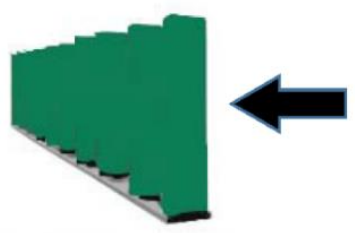

Late molding processing and installation
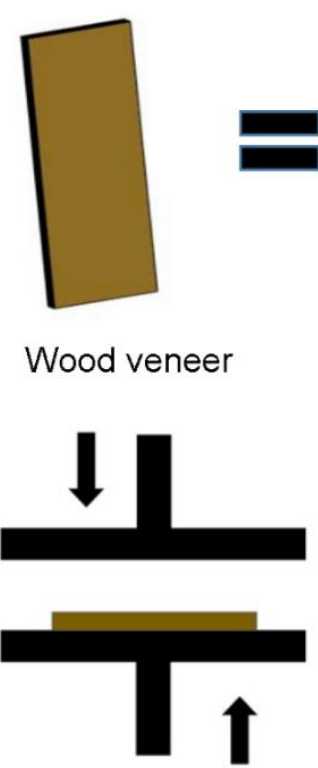

Hot press the veneer by thermal compressing machine

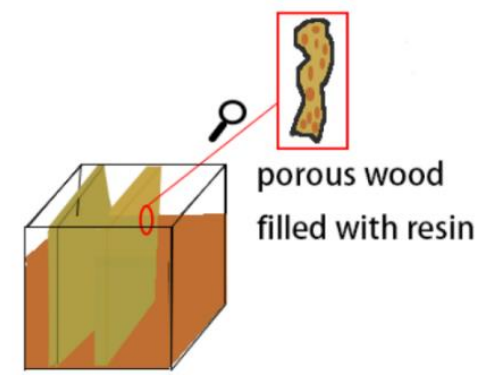

Impregnated veneer

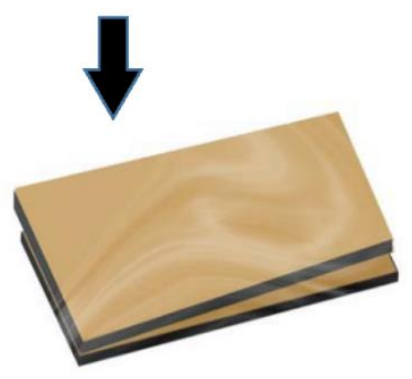

Drying

Fig. 1. Preparation process of the WAB
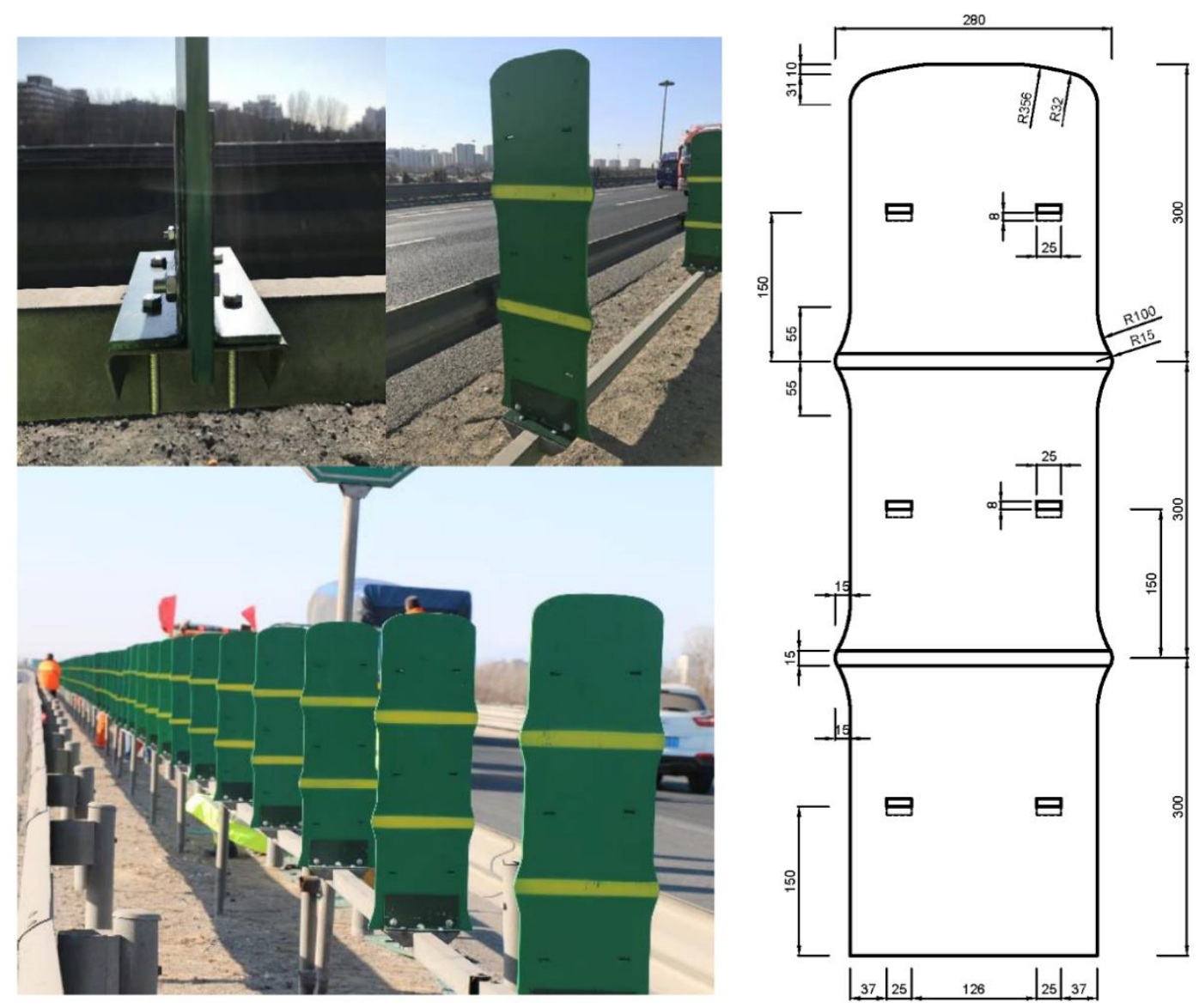

Fig. 2. Dimensions and installation situation of the WAB 
The hot-pressing time of the second stage was 60 to $120 \mathrm{~s}$, and the hot-pressing pressure was 1.0 MPa. The hot-pressing time of the third stage was 10 to $60 \mathrm{~s}$, and the hotpressing pressure was $0.5 \mathrm{MPa}$. The pressure was then relieved.

The preparation process of the WAB is depicted in Fig. 1, and dimensions and installation situation of the WAB is shown in Fig. 2.

\section{WAB prepared in a factory}

Gradient hot-pressing technology was adopted to prepare a wooden anti-glare board in a factory. The hot-pressing temperature was maintained at 120 to $150{ }^{\circ} \mathrm{C}$. The hotpressing time of the first stage was 800 to $1000 \mathrm{~s}$, and the hot-pressing pressure was 1.5 $\mathrm{MPa}$. The hot-pressing time of the second stage was 500 to $600 \mathrm{~s}$, and the hot-pressing pressure was 1.2 MPa. The hot-pressing time of the third stage was 150 to $300 \mathrm{~s}$, and the hot-pressing pressure was 1.0 MPa. The board was then naturally cooled to room temperature, and the pressure was slowly released over 3 to $4 \mathrm{~h}$. The WAB was then cut into sizes of $0.9 \mathrm{~m} \times 0.27 \mathrm{~m}$. The structure was made to look like bamboo, and the surface was decorated with bright-green weather-resistant anticorrosive paint.

As a material used outdoors, the WAB must be susceptible to the actual outdoor climate. Therefore, outdoor conditions throughout the year need to be simulated before being used on highways. Therefore, the strength of the WAB needs to be tested by simulating supersaturated weather conditions in the laboratory. Figure 3 presents the installation effect of the WAB on a highway under different weather conditions in four seasons. Different weather conditions in four seasons are mainly shown as wind in spring, hot sun in summer, heavy rain in autumn, and freezing snow in winter and the corrosion caused by the snowmelt agent (salt, for example) from a snowplow.

(a)

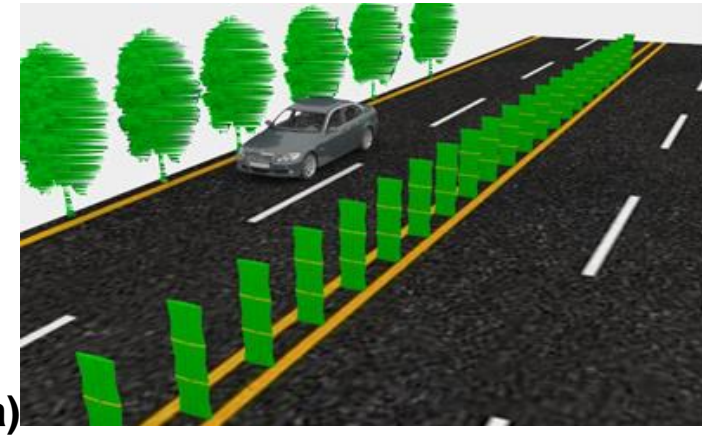

(c)

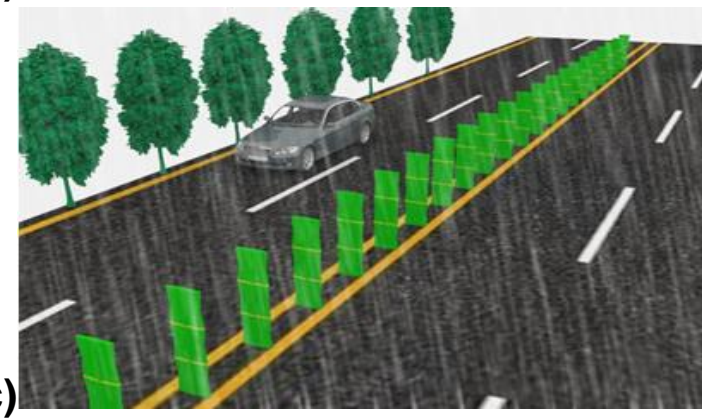

(b)

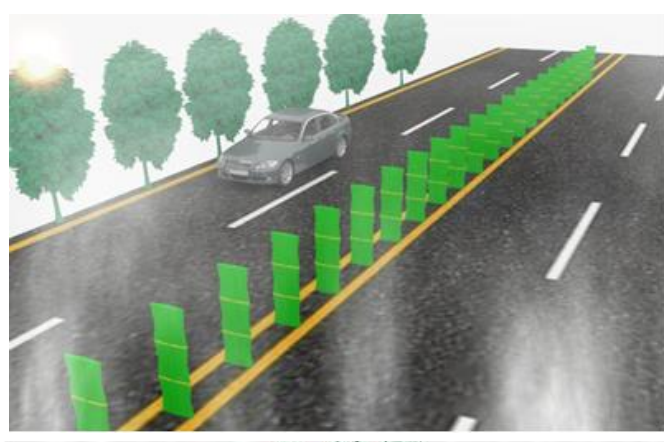

(d)

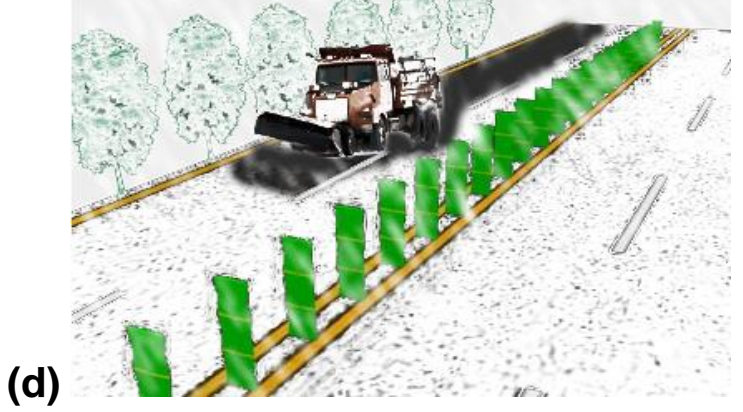

Fig. 3. Simulation of the road installation of the factory-prepared WABs: (a) wind in spring; (b) heat in summer; (c) rain in autumn; (d) snow in winter 


\section{Performance measurement of the WAB}

The static bending strength, elastic modulus, and bending resistance of the WAB were measured according to the GB/T 17657 (2013). The wind load test method was measured by the National Traffic Safety Facilities Quality Supervision and Testing Center (Transportation Engineering Supervision and Testing Center). The reference standard was GB/T 24718. (2009).

\section{Determination of the Weatherability of Eucalyptus Wood}

The general scheme for weathering resistance and impact resistance testing is shown in Fig. 4.

(a)

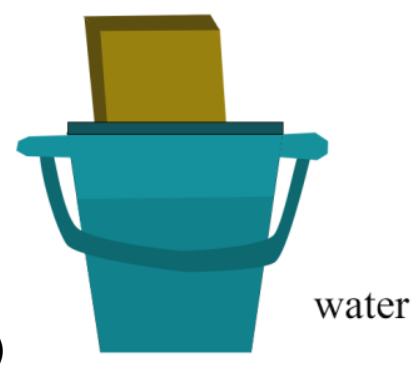

(b)

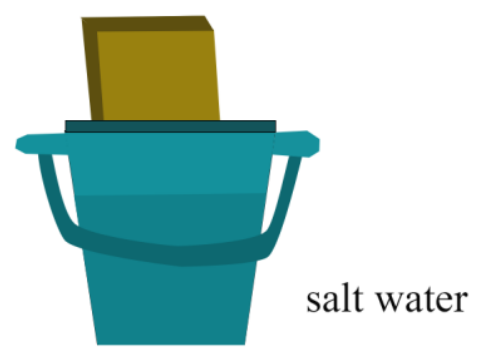

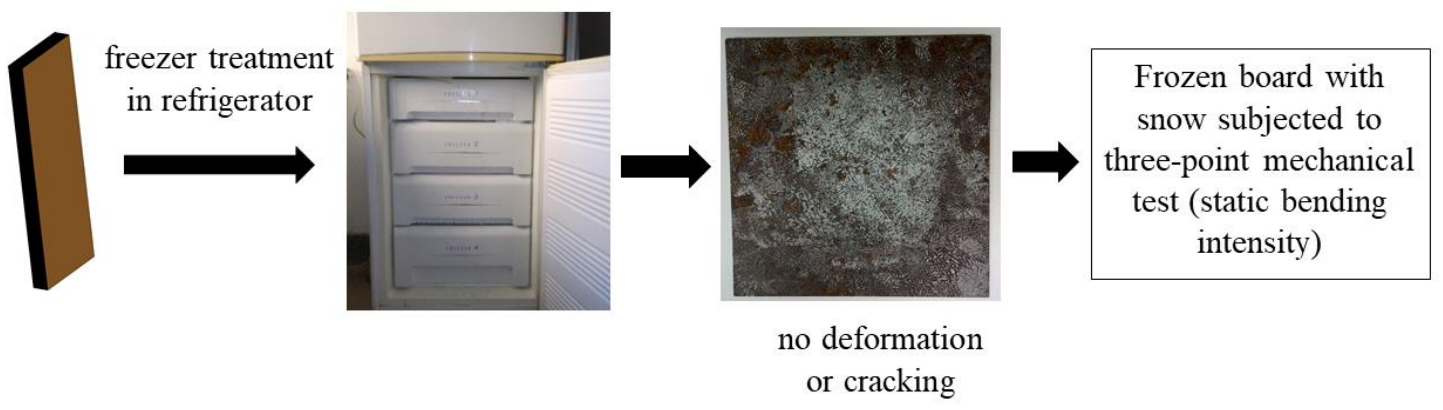

(c)

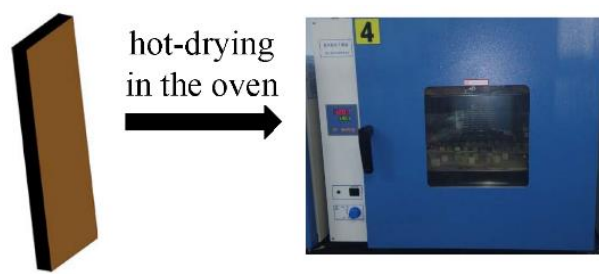

(d)

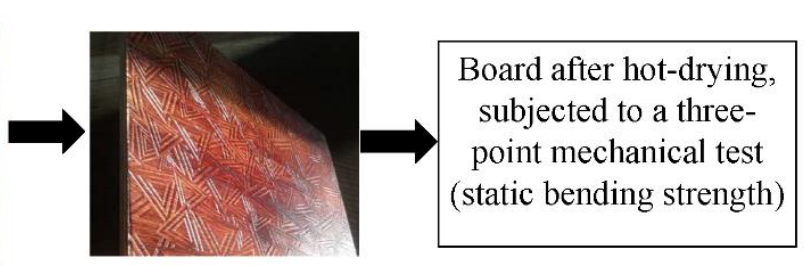

no deformation or cracking
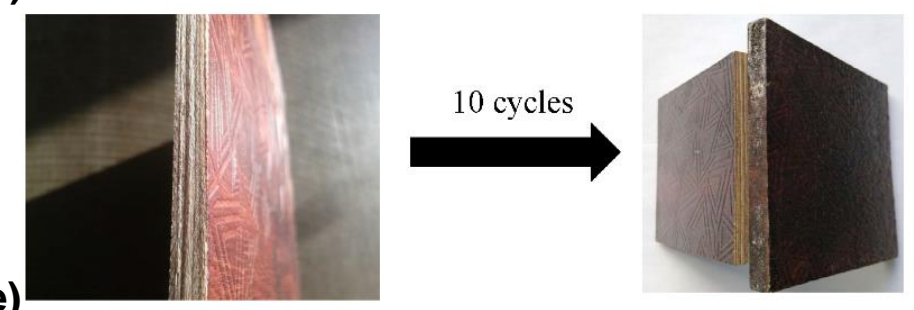

Fig. 4. Schematic diagrams of weather resistance and impact resistance tests 
Strategy A: A simulation test of the weather resistance of the WAB in four seasons was conducted. The seven-layer eucalyptus plywood was soaked in water for $24 \mathrm{~h}$ at room temperature, refrigerated at $-10^{\circ} \mathrm{C}$ for $24 \mathrm{~h}$, and dried at $50{ }^{\circ} \mathrm{C}$ for $4 \mathrm{~h}$.

Strategy B: A simulation test of the weather resistance of the WAB after snowmelt spraying was conducted. The seven-layer eucalyptus plywood was soaked in a saturated sodium chloride solution for $24 \mathrm{~h}$ at room temperature, refrigerated at $-10{ }^{\circ} \mathrm{C}$ for $24 \mathrm{~h}$, and dried at $50{ }^{\circ} \mathrm{C}$ for $4 \mathrm{~h}$.

Strategy $C$ : A simulation test of the impact resistance of WABs in low-temperature conditions in the winter was conducted. The test method for the static bending strength of frozen wet anti-glare board soaked in water (SFBW) and frozen wet anti-glare board soaked in brine (SFBB) was as follows. After freezing for $24 \mathrm{~h}$ and drying for $4 \mathrm{~h}$, the WABs were examined with a universal mechanical testing machine from Jinan Gold Testing Group Co., Ltd. (Shandong, China). The reference standard was GB/T 17657 (1999) for the measurement of the strength and modulus of elasticity of the static bending of wood-based panels.

Strategy D: A simulation test of the impact resistance of WABs under hightemperature conditions in the summer was conducted. The test method and reference standard for static bending strength of dry anti-glare board soaked in water (SDBW) and dry anti-glare board soaked in brine (SDBB) were the same as those in Strategy C.

The size of all specimens was $280 \times 50 \times 10 \mathrm{~mm}^{3}$. All the specimens obtained by sawing were covered with anticorrosive paint on the upper and lower surfaces, but no anticorrosive paint was applied on the exposed sides.

The weatherability test process was as follows. The specimens in two experimental groups $a$ and $b$ were both subjected to 10 weatherability test cycles once per day for 11 days, and the static strength and elastic modulus of the specimens were tested after freezing and drying.

The test method of the weight gain was as follows. Before the experiment, the weight of each WAB was recorded as $W_{1}$. During the experiment, the WAB was frozen for $24 \mathrm{~h}$, and its weight after removal was measured as $W_{2}$. Calculation for percentage of weight gain:

$$
\text { Weight gain }=\left(W_{2}-W_{1}\right) / W_{1} \times 100 \%
$$

\section{Determination of Fire Resistance of Eucalyptus Wood}

The flame-retardant performance of the seven-layer eucalyptus plywood was tested with a JF-3 oxygen index tester (Jinan Analytical Instrument Co., Ltd., Shandong, China). The reference standard was GB/T 2406.2 (1992).

\section{RESULTS AND DISCUSSION}

\section{Mechanical Strength}

Influences of different veneer materials, veneer arrangements, and metal mesh composites on the mechanical properties of the WAB

It was found that different tree species, namely PV, EV, and BV, had a direct influence on the properties of the WABs, such as their adhesion, bending strength, and elastic modulus. Compared with EV, PV is soft with a low density and hardness; however, its surface is flat and smooth, easy to process, and has no spindles. It is widely used in the 
wood processing industry. BV has a fine wood grain, strong toughness, good corrosion resistance, and is easy to process. It is mainly used in furniture and veneers, but it is more expensive than PV and EV. Due to their differences, these three types of veneers were investigated in the present study.

As can be seen from Figs. 5, 6, and 7, different materials and veneer arrangements had great influences on the strength of WABs. For each material, the WABs with unidirectional arrangement had the highest mechanical strength, followed by the WABs with alternating arrangement. This was caused by the different material characteristics of the wood veneers, such as their fiber length, hardness, density, etc.
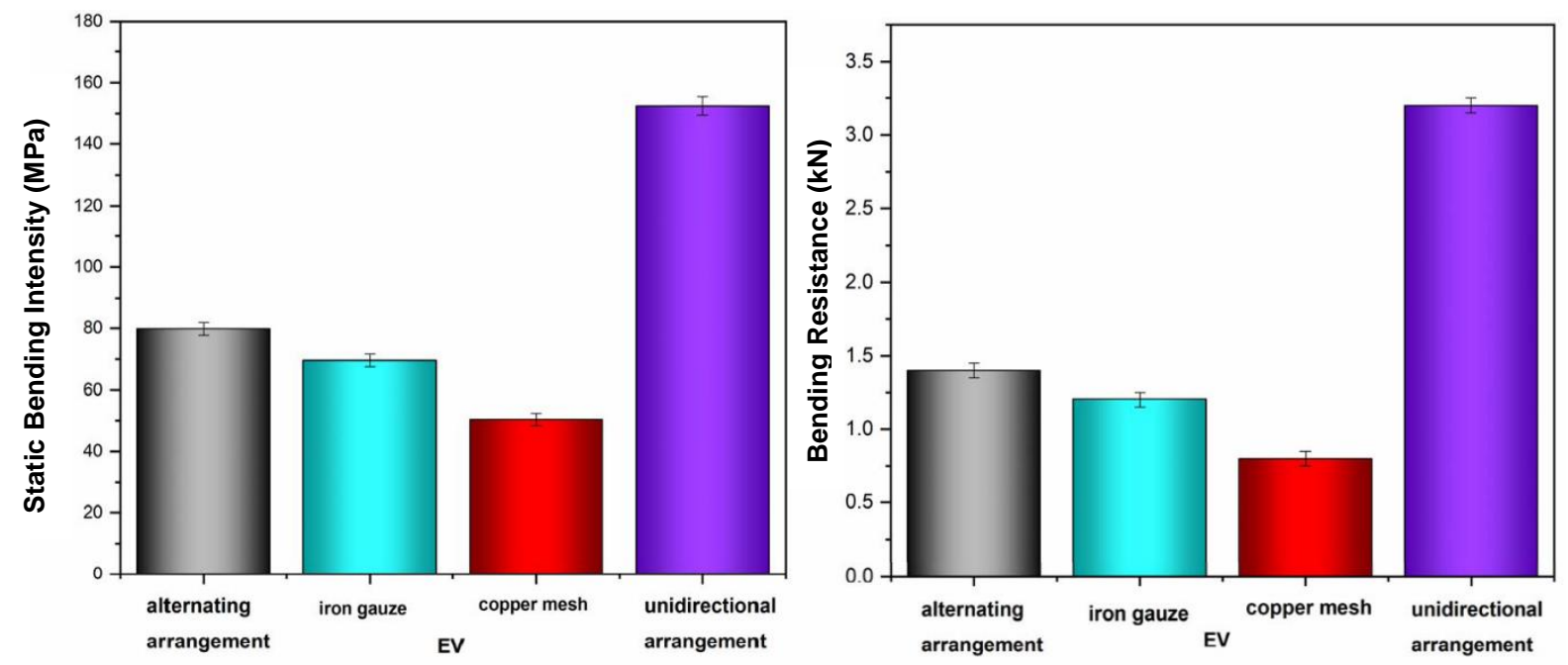

Fig. 5. The effects of different veneer arrangements, and the addition of metal meshes on the mechanical properties of eucalyptus veneer (EV)
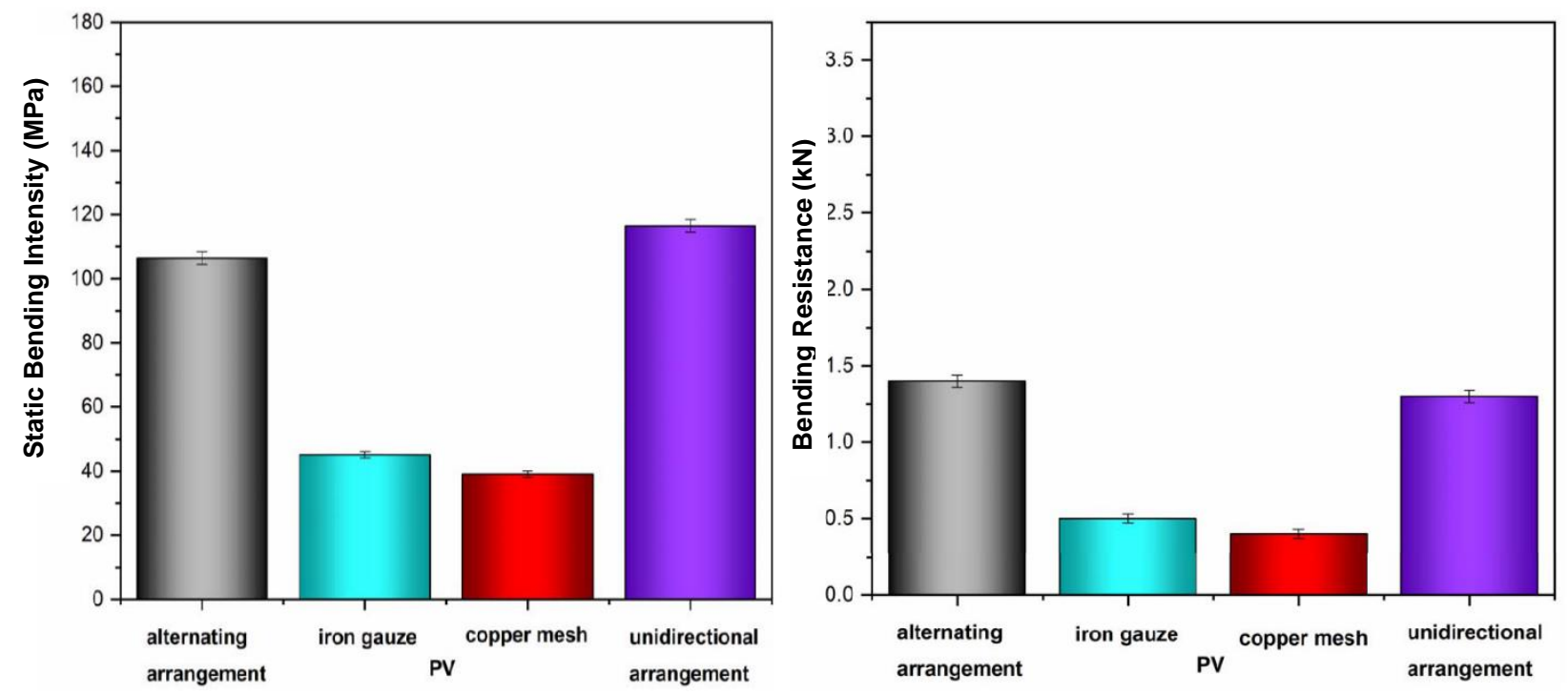

Fig. 6. The effects of different veneer arrangements, and the addition of metal meshes on the mechanical properties of poplar veneer (PV) 

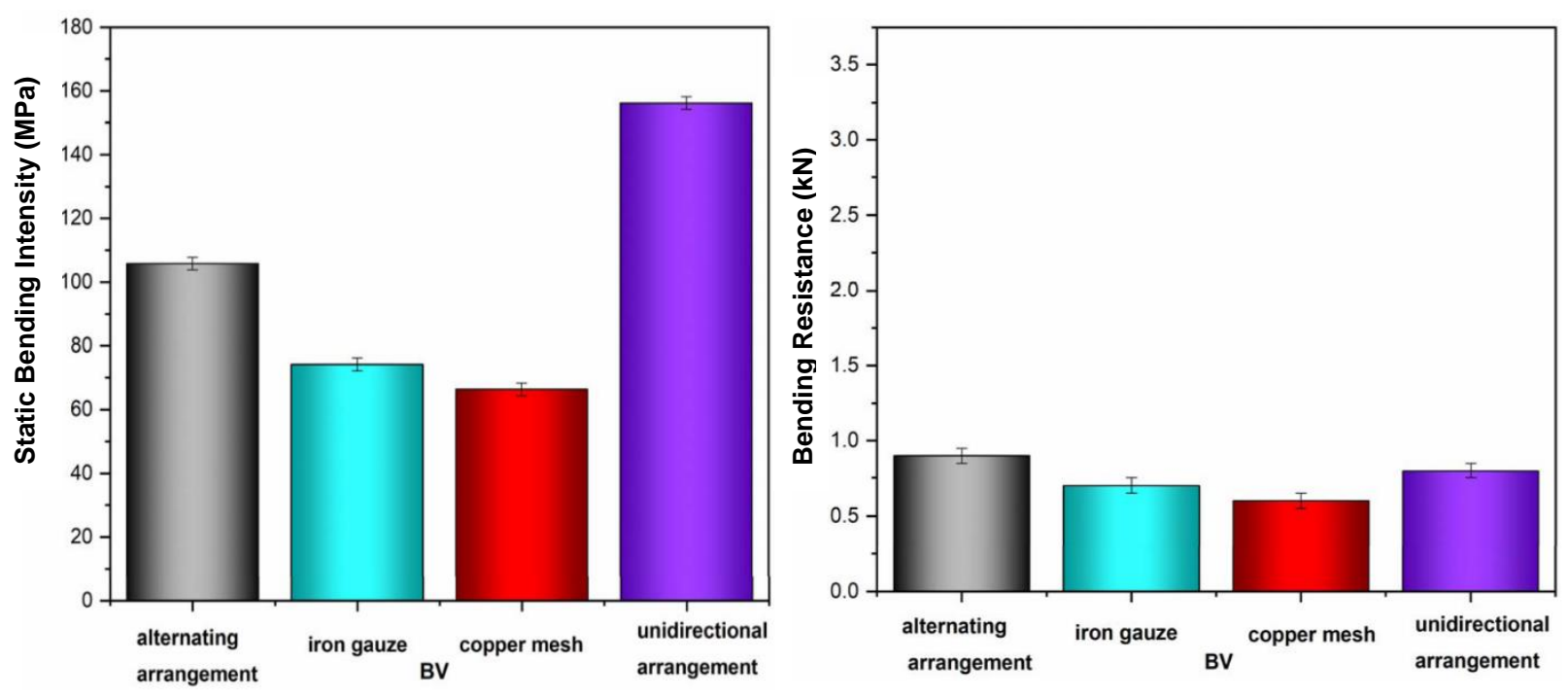

Fig. 7. The effects of different veneer arrangements, and the addition of metal meshes on the mechanical properties of basswood veneer (BV)

At first, the author suspected that adding metal net to the anti-glare board would enhance the mechanical properties of the anti-glare board by acting as cross-linking, just like reinforcing steel bars in concrete or adding metal mesh in automobile tires. So, a layer of copper mesh or iron gauze was added between the third and fourth wood veneer layers in an alternating arrangement to prepare the wood-metal composite material. The results demonstrated that the mechanical properties of the anti-glare board with metal mesh were not enhanced, but decreased. The result was not as expected, and the results were attributed to the fact that the interfacial bonding strength between the metal and the wood was too weak to bond together well.

In addition, for each material, the static bending strengths of the WABs with the unidirectional arrangement were higher than those with the alternating arrangement; this was because the wood fiber was arranged in the same direction as the striping was arranged, so the anisotropy of the material was more obvious, resulting in stronger mechanical properties.

However, the adhesion force of wood fiber was weak in the vertical direction, which led to the weak mechanical properties of the material in this direction. Moreover, because the veneers were obtained by rotary cutting, they experienced the stress of bending and contracting, and the stress was more concentrated after the veneer layers were arranged in the same direction. Therefore, the entire surfaces of the veneer layers arranged along the same direction would bend if the WAB was installed for a period of time. In addition, the static bending strength of the staggered EV was $79.8 \mathrm{MPa}$, which was higher than the 74.08 $\mathrm{MPa}$ static bending strength of the phenolic resin-impregnated plywood under a $2.5-\mathrm{MPa}$ hot-pressing pressure.

The arrangement of veneers of different materials had a great influence on the bending strength of the WABs. Eucalyptus fiber is coarse and hard, and the WAB prepared with EV had a higher hardness and bending strength. Basswood fiber is weak, loosely arranged, has a poor hardness and bending ability, and it also had a poor interface with the metal mesh; while it is more slender than eucalyptus fiber and has good flexibility, the fiber is less rigid (Guan et al. 2016; Yu et al. 2019). In contrast, the surface of the WAB made with EV was more rigid; hot-pressing and cooling did not easily cause bending 
deformation, and the board could face resistance to a strong wind load. Among the WABs made of EV, that with layers arranged along the grain had the highest flexural strength, followed by that with an alternating arrangement, which was also due to the anisotropy of the wood fibers. However, while the arrangement of the veneers along the grain direction resulted in an increased bending strength of the WABs, the likelihood of deformation problems, such as internal stress, was increased. In contrast, for WABs with an alternating arrangement, the internal stresses in different directions canceled each other out. Moreover, the bending strengths of all sides were consistently upward, and the board surface was flat and did not deform after hot-pressing and cooling. Therefore, the WABs made of EV with an alternating arrangement and without the inclusion of a metal mesh are the most suitable.

In summation, the choice of EV for the construction of a WAB is suitable if it is placed with an alternating arrangement and not combined with a metal mesh. The WAB prepared by the gradient hot-pressing process after impregnation with phenolic resin was found to have good mechanical strength.

\section{Wind load performance improvement of the WAB and a comparison of market products}

Anti-glare boards are often damaged or even broken under wind load, and their maintenance costs are high. An anti-glare board that is prone to be blown off its fixture will have some small fine lines at its base caused by swaying due to wind. The stress at the root of the WAB is the most concentrated and the moment is the largest. Therefore, the base of an anti-glare board is the most vulnerable to cracking, and its wind resistance plays an important role in the stress analysis of anti-glare boards under wind load (Li 2010).

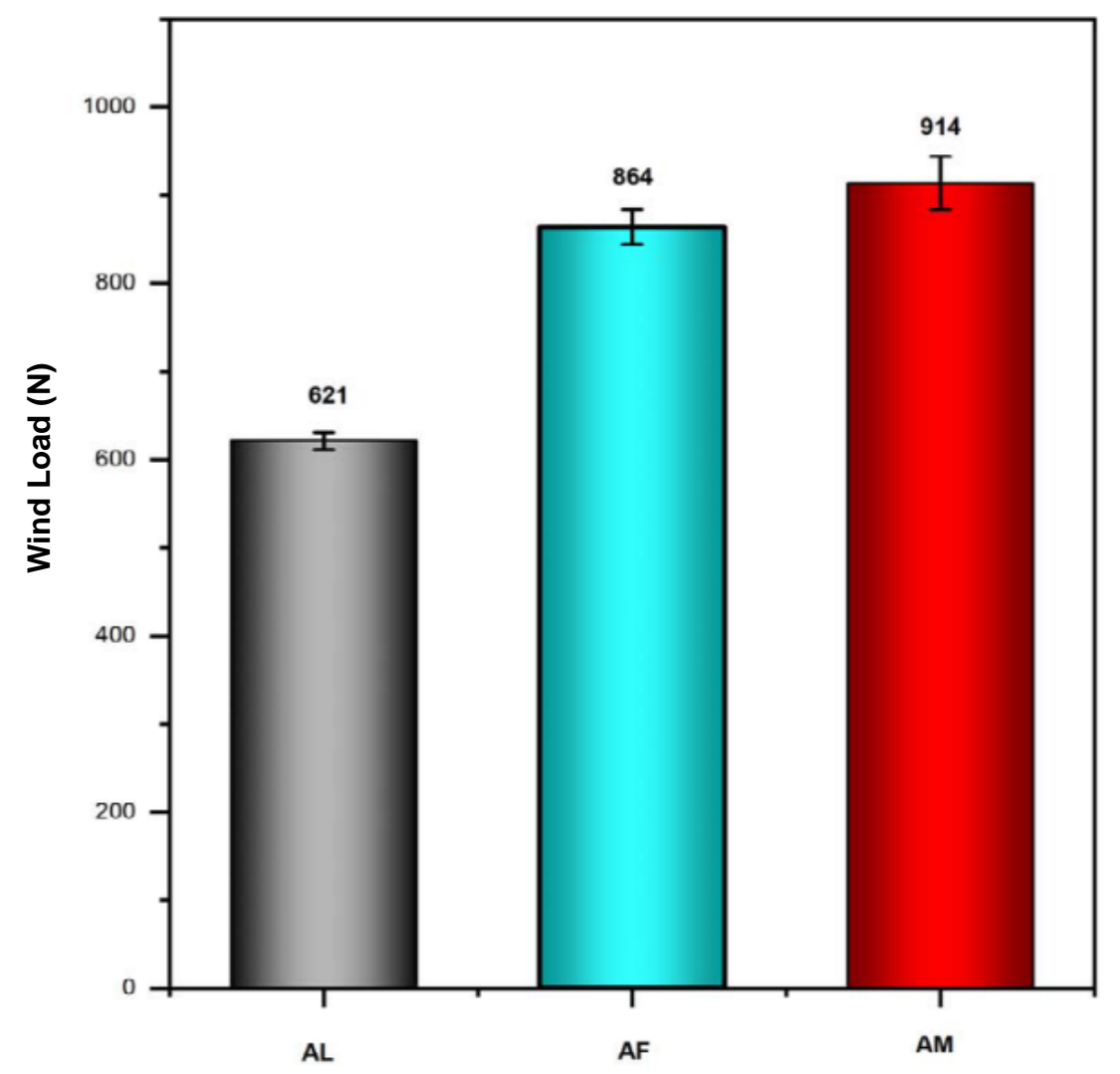

Fig. 8. Comparison of the wind load resistances of three types of anti-glare boards; AL: laboratory-prepared WAB; AF: factory-prepared WAB; AM: market-available FRP board 
A comparison of the wind load resistances of three types of anti-glare boards is presented in Fig. 8. The WAB prepared in the Beijing Forestry University laboratory (AL) had a wind load resistance of $621 \mathrm{~N}$ and an anti-deformation value of $1.7 \mathrm{~mm} / \mathrm{m}$, which both meet the national standard requirements of GB/T 24718 (2009). After improvement, the WAB made in a factory (AF) in 2016 exhibited a noticeable improvement of the wind load resistance, the value of which was $864 \mathrm{~N}$. The wind load resistance of WAB exceeded the national standard GB/T 24718 (2009) and its performance was close to that of a highgrade FRP anti-glare board available on the market (AM).

\section{Weather Resistance of WAB}

The results of the static bending strengths of the WABs in the weathering cycle experiment are shown in Fig. 9. Anti-glare boards are mainly placed in harsh outdoor environments. Traditional metal, FRP, and plastic anti-glare boards are prone to corrosion, breaking, and other aging phenomena in these environments, so their weatherability is an important testing standard for their application. Moreover, the strength of the novel WAB required investigation because glass, steel, and plastic anti-glare boards are vulnerable to brittle fracture when they are frozen and subjected to high winds or the impact of vehicles.

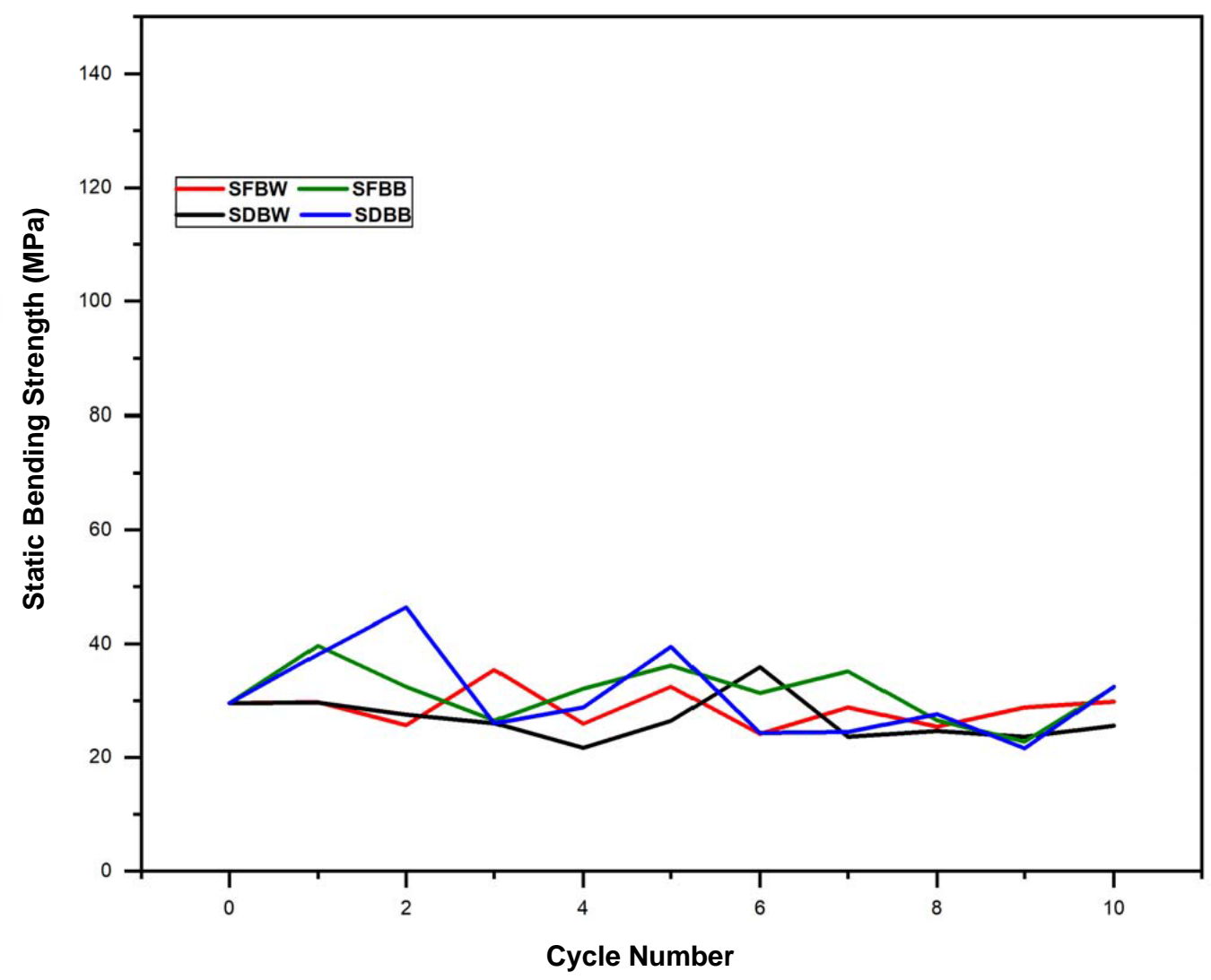

Fig. 9. The static bending strength of the WABs in the weathering cycle test; SFBW: Static bending strength of frozen wet anti-glare board soaked in water; SDBW: Static bending strength of dry anti-glare board soaked in water; SFBB: Static bending strength of frozen wet anti-glare board soaked in brine; SDBB: Static bending strength of dry anti-glare board soaked in brine 
As exhibited in Fig. 9, the WABs were subjected to soaking, freezing, and hotdrying. The average bending strength did not decrease remarkably after 10 cycles of heating for $24 \mathrm{~h}$, followed by freezing for $24 \mathrm{~h}$, and then drying. During the winter, a large amount of snow-removal solution is sprayed to remove snow on highways. Its main component is sodium chloride, which causes a certain degree of corrosion to auxiliary devices such as anti-glare boards.

(a)

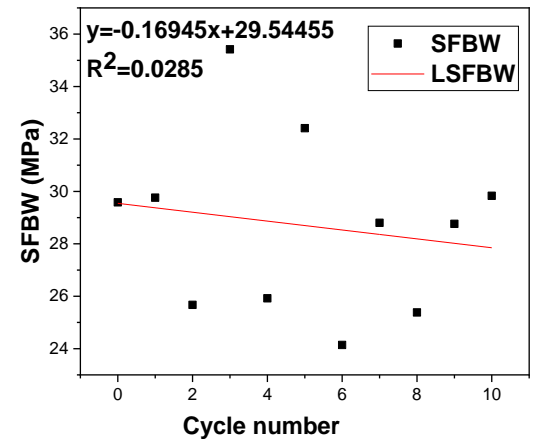

(c)

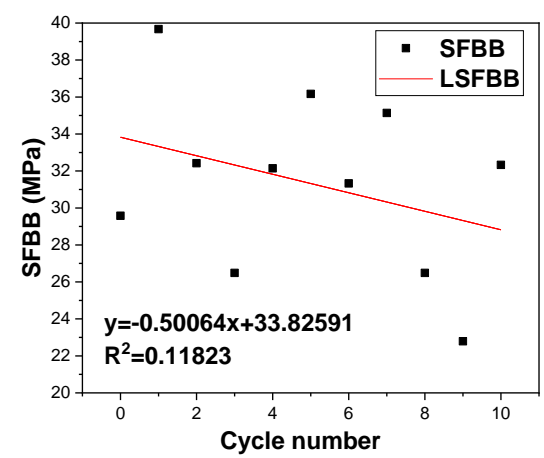

(b)
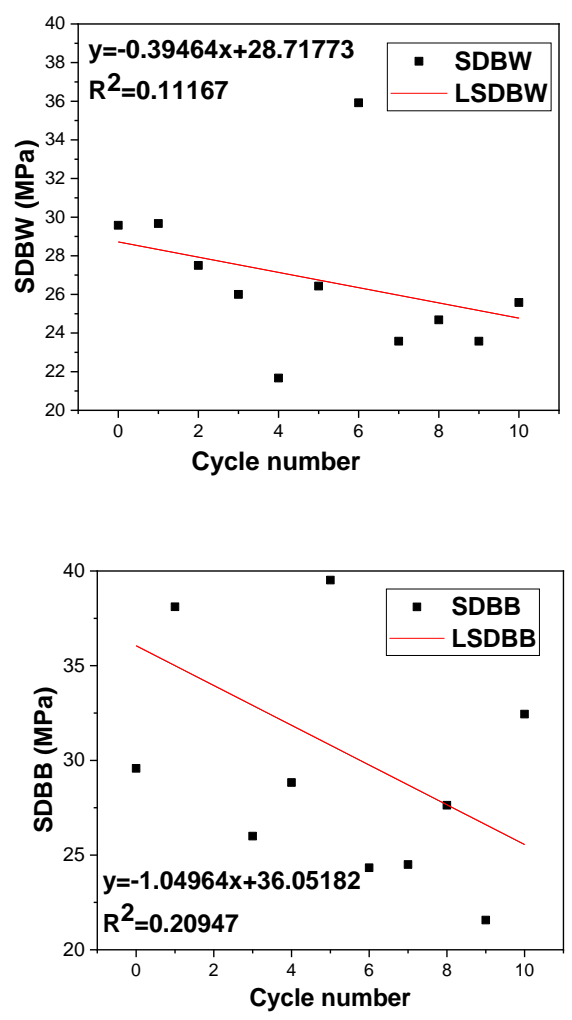

Fig. 10. (a) Static bending strength of frozen wet anti-glare board soaked in water (SFBW) and linear regression of static bending strength of frozen wet anti-glare board soaked in water (LSFBW); (b) Static bending strength of dry anti-glare board soaked in water (SDBW) and linear regression of static bending strength of dry anti-glare board soaked in water (LSDBW); (c) Static bending strength of frozen wet anti-glare board soaked in brine (SFBB) and linear regression of static bending strength of frozen wet anti-glare board soaked in brine (LSFBB); (d) Static bending strength of dry anti-glare board soaked in brine (SDBB) and linear regression of static bending strength of dry anti-glare board soaked in brine (LSDBB)

To further determine the influence of the weather cycle on the WABs, regression models were established based on the collected data. As presented in Fig. 10, it was found that, after 10 experimental cycles, the data measured under different conditions exhibited gradually declining trends. However, by comparing the slopes of the regression lines in Figs. 10(a through d), it is evident that the slope of the graph in Fig. 10c (-1.04694) is the lowest, and the absolute value of the slope is the highest. Therefore, the strength of the brine-soaked WAB after drying decreased the most obviously, indicating that the effect of saline immersion on the $\mathrm{WAB}$ was the greatest, and that high-salinity conditions can accelerate the aging of WABs. 


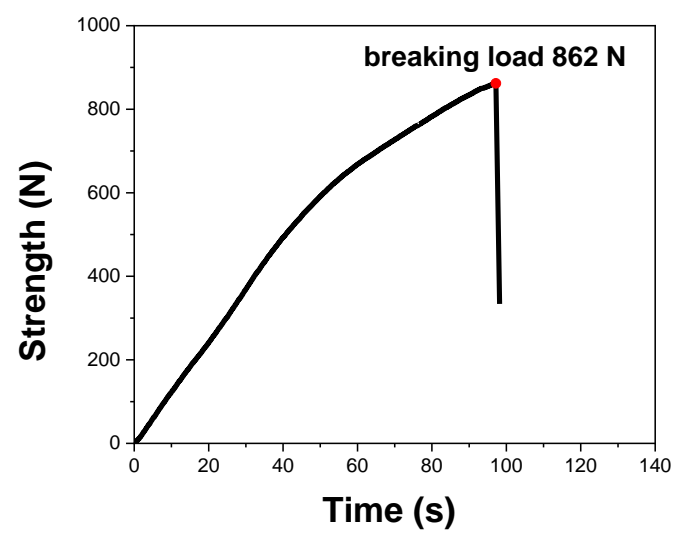

(a)

Time (s)

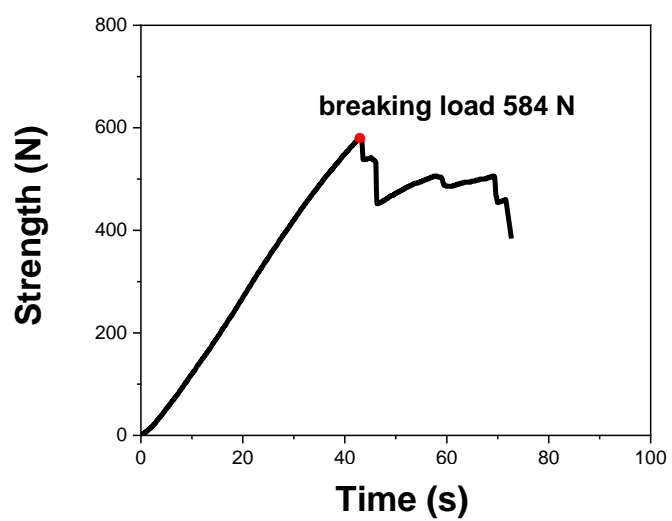

(b)

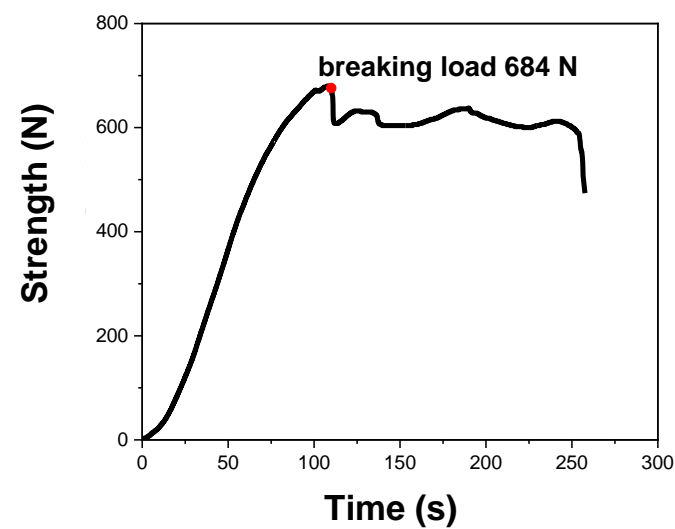

(c)

Fig. 11. Results of the static flexural strength test of the WAB: (a) Simulated annual cycles 0 through 6, during which the specimen fractured; (b) Simulated annual cycle 7, during which the specimen experienced segmented fracture; (c) Simulated annual cycle 8, during which the specimen exhibited obvious plastic deformation

Figure 11a presents cycles 0 through 6 of the flexural strength test. Fracture occurred when the pressure of the WAB increased to the maximum, and failure occurred immediately after the fracture. At this time, the WAB had a tight adhesive layer and high cementation strength, and the entire WAB was uniformly compact. As shown in Fig. 11b, during cycle 7, the WAB fractured in layers. As exhibited in Fig. 11c, during cycle 8, the WAB exhibited obvious plastic deformation, while the fracture of the lumber was not 
obvious. Due to the cracking of both ends, the stress of the wood was reduced under the same conditions. The viscoelasticity of wood makes the novel WAB different from antiglare boards made of other materials; therefore, when hit by external forces, the WAB can absorb these external forces, which reduces its damage.

The performance changes of the $\mathrm{WAB}$ in the two weatherability experiments revealed the following. In the early period of 0 to 6 simulated annual cycle experiments, an exposed WAB did not crack and stratify, its strength and dimensions did not change obviously, and its overall rigidity remained high. Between 7 to 10 simulated annual cycle experiments, the sides of the exposed wooden anti-glare board gradually absorbed water, which led to the gradual aggravation of layered cracking and the decrease of the mechanical strength and other properties. However, its static bending strength and elastic modulus did not degrade to less than those of a brand-new FRP anti-glare board due to the toughness of the multi-layer wood material.

WABs are not fixed on the ground, but on shelves half a meter high in the middle of the highway's central isolation belt. Therefore, impact bending failure is the main occurrence of the anti-glare board in traffic accidents. As a multi-layer wood material, WAB may bend but not break instead of being brittle fractured when a truck drives over the WABs, which can prevent it from falling off the shelf half a meter high in the middle of the highway's central isolation belt onto the highway, and then causing a secondary accident.

The weathering cycle tests $a$ and $b$ were conducted under harsh experimental conditions, and after $24 \mathrm{~h}$, water had fully penetrated the conduits and gaps of the wood fiber. Because the volume of water increased after freezing for $24 \mathrm{~h}$, the water expanded in the gaps of the wood, thereby causing the volume expansion of the entire WAB. After another $50{ }^{\circ} \mathrm{C}$ drying treatment, the ice between the wood fibers melted, dried, and evaporated, resulting in the strong internal stress of the entire board; this easily caused the cracking of the board layers and the destruction of the rubber layer and the wood structure itself. Such test conditions can fully simulate natural conditions, so it is reasonable for a single experimental cycle to simulate the outdoor natural aging effects during one year.

To place these results in perspective, there is really no evidence that accelerated weathering tests can give a reliable prediction of WAB performance when exposed outdoors, so WAB's 10-year service life was unpredictable. However, the present results showed that WAB can withstand more than 10 simulated annual cycles of artificial weathering.

Figure 12 presents the variations of the relative weight gain of the WABs during the experiment. After soaking in water and freezing, the WAB increased in weight, and the increasing trend exhibited no noticeable difference in the first 6 cycles, after which the relative weight gain increased remarkably. After cycle 7, the relative weight gain of the WAB soaked in water remarkably increased. In contrast, the relative weight gain of the WAB soaked in brine began to remarkably increase after cycle 6 . This finding indicates that immersion in brine led to the entry of more water and accelerated cracking. Therefore, the snow-removal solution used on highways in the winter can have a similar effect on WABs.

The process of $\mathrm{WAB}$, the veneer treatment, and hot-pressing, is similar to that of a wooden floor. Therefore, Fig. 13 shows how the performance of A and B differs by comparing their static bending strengths horizontally. 

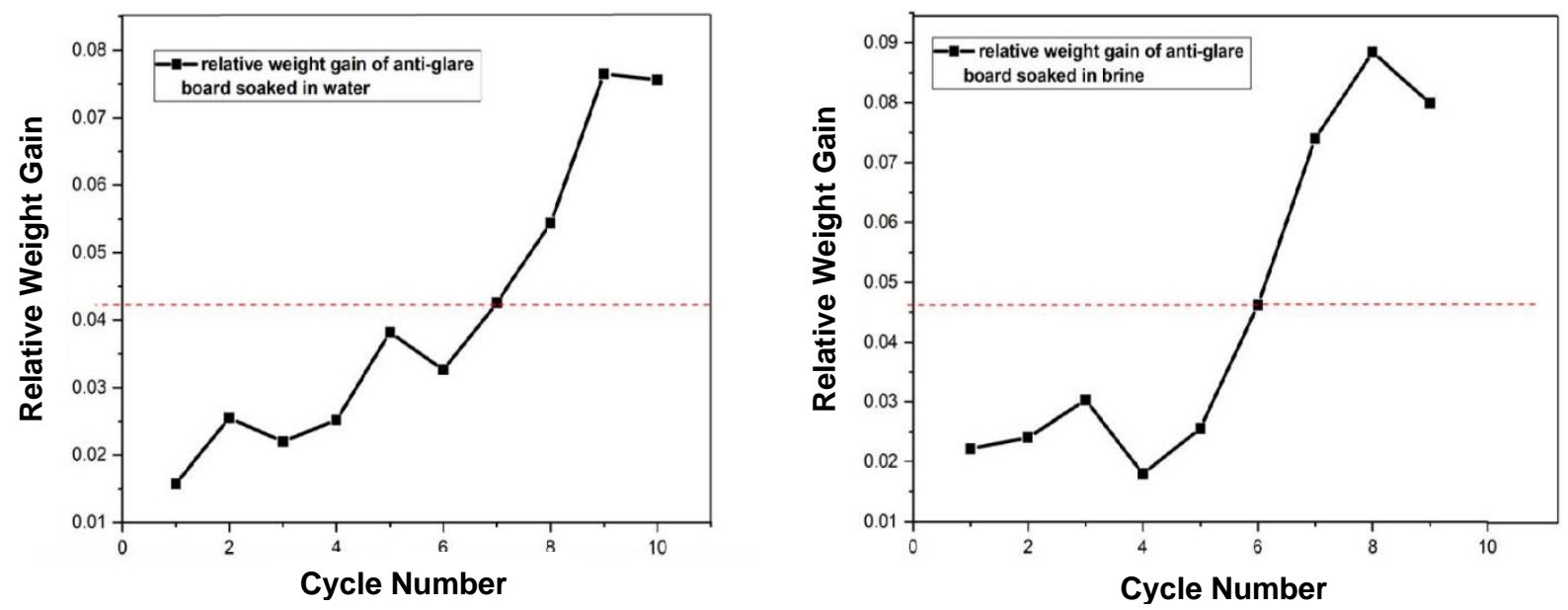

Fig. 12. Changes in the relative weight gain of the WABs during the experiment

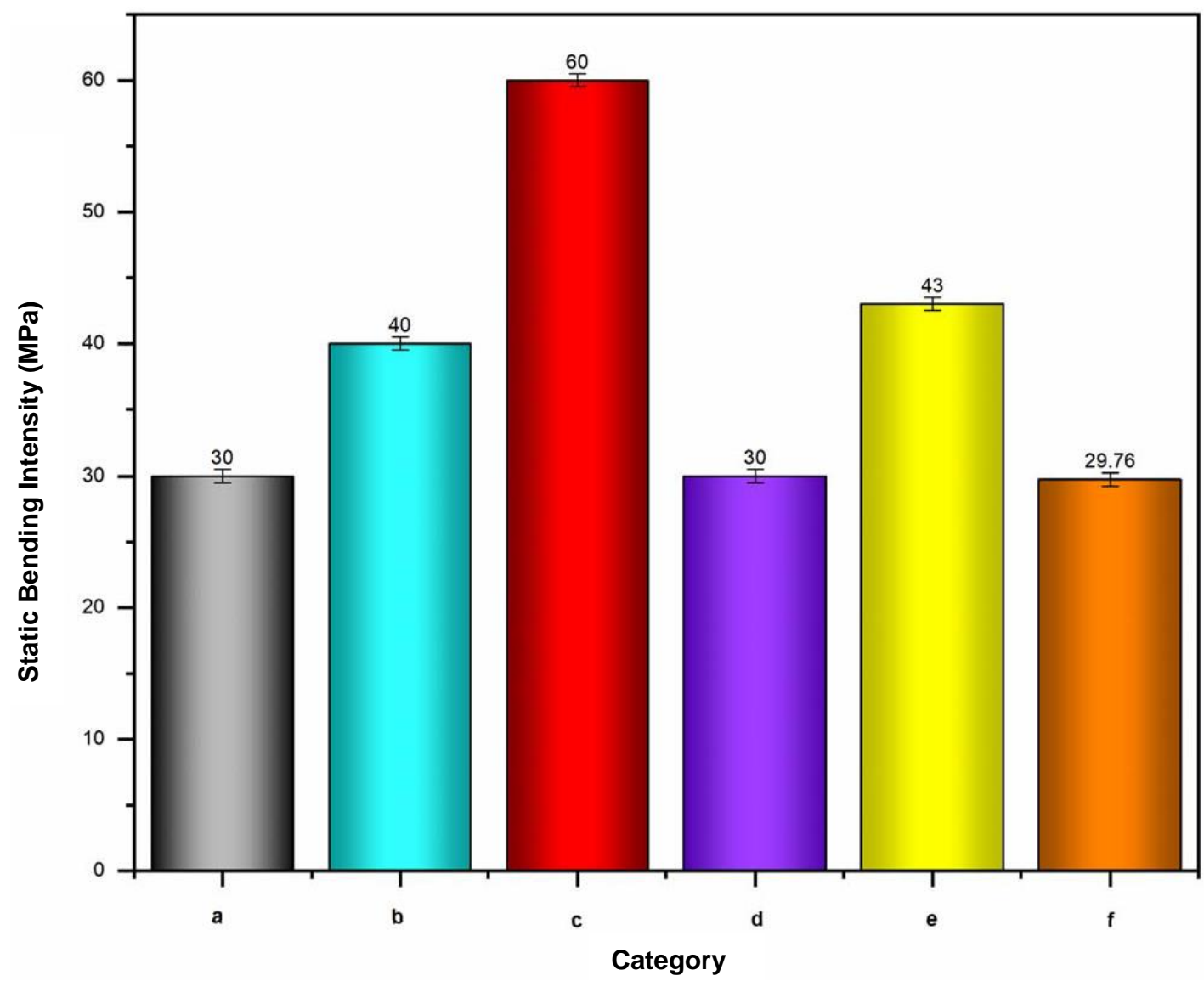

Fig. 13. Contract of static bending strengths of floor materials and the WAB: (a) Parquet floor; (b) outdoor anti-corrosive solid wood floor; (c) reconstituted wood floor; (d) Solid wood composite plywood; (e) impregnated WAB; (f) glued WAB

Figures $13 \mathrm{e}$ and $13 \mathrm{f}$ present the static bending strengths of the WABs fabricated with resin impregnation and glue, respectively. Regardless of the fabrication method, the strength of the WABs reached the standards of the parquet floor (a) and solid wood 
composite plywood (d). As the sizing amount of the WAB fabricated with resin impregnation (e) was much higher than the glued WAB (f), its strength was higher.

\section{Flame-retardant Property of the WAB}

The flame-retardant properties of the specimens were tested 15 times, and the average values were reported. As presented in Fig. 14, the limited oxygen index (LOI) of the WAB was $26.1 \%$. In addition, the LOI of ordinary poplar veneer (PV) has been reported as $23.3 \%$, and the national standard GB/T 2406.2 (1992) of the LOI of flame-retardant wood (FRW) is $>27 \%$. In general, a material with an LOI of $<22 \%$ is considered an easily flammable material (EFM), that with an LOI between 22 and $27 \%$ is a flammable material (FM), and that with an LOI of $>27 \%$ is a nonflammable material (NFM).

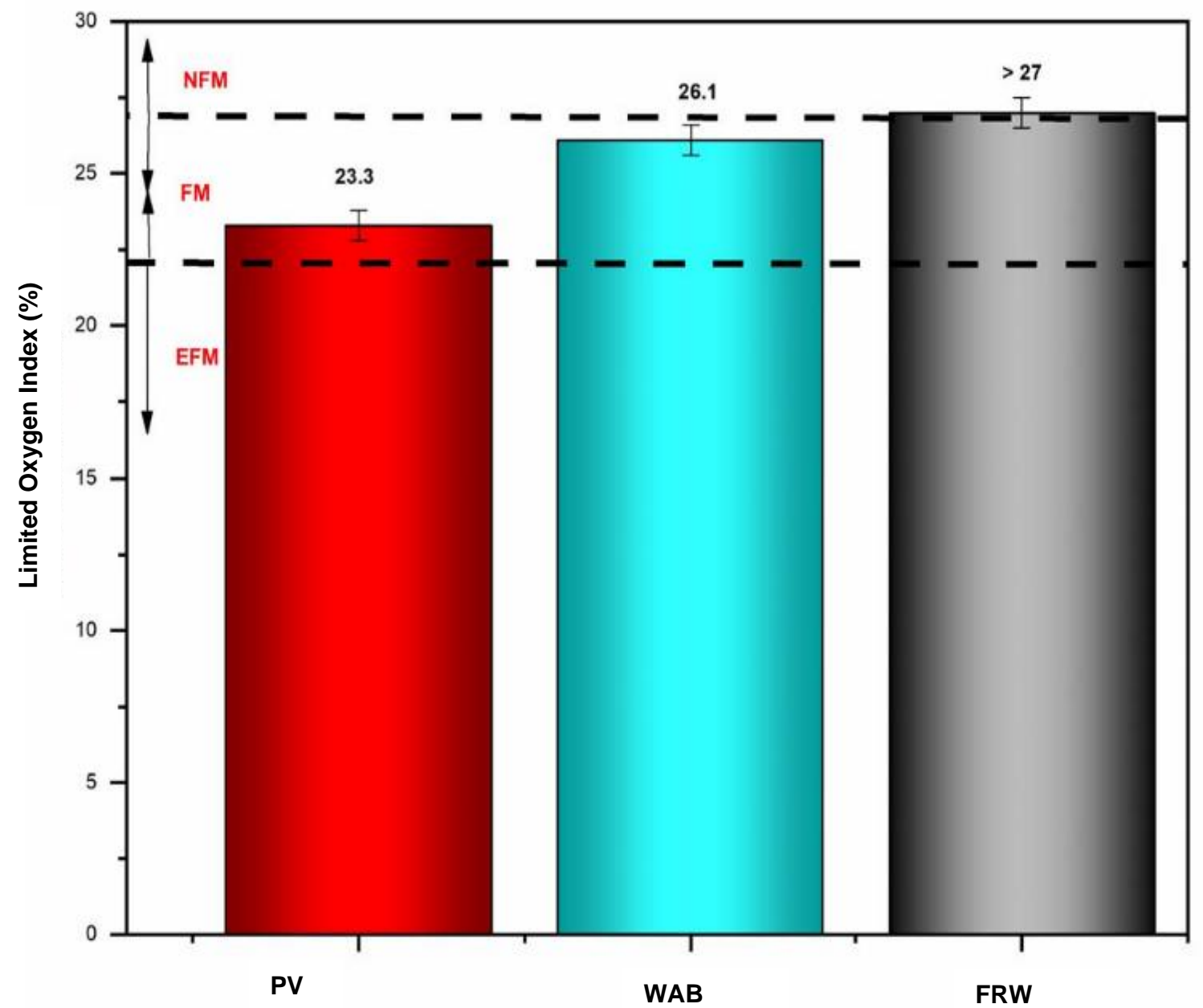

Fig. 14. LOls of anti-glare boards made of different materials

According to Fig. 14, ordinary PV is a combustible material. While the WAB is also categorized as a combustible material, its LOI was higher than that of PV. Flameretardant wood is a refractory material, and its LOI was similar to that of the WAB. This was mainly because the WAB prepared in this study was fully penetrated by the phenolic resin with good thermal stability and highly crosslinked strength. Therefore, compared with ordinary PV, the flame-retardant property of the WAB was greatly improved. In summary, the WAB exhibited good flame-retardant performance. 


\section{CONCLUSIONS}

1. A wooden anti-glare board (WAB) composed of eucalyptus layers arranged along the grain direction and without the addition of a metal mesh exhibited good comprehensive performance in line with China's national standards.

2. The proposed WAB had a reduced wind load resistance compared to a fiber-reinforced plastic (FRP) anti-glare board, but a higher wind load resistance than anti-glare boards made of engineering plastics.

3. The proposed WAB made of a phenolic resin-impregnated wood composite is characterized by a low cost, good weather resistance, and recyclability, and is expected to be an effective long-term replacement for existing anti-glare boards. Thus, the findings of this research provide new ideas and methods for the recycling of highway greening waste, as well as technical support for the effective replacement of existing non-renewable anti-glare boards with novel low-cost and environmentally friendly wooden anti-glare boards.

\section{ACKNOWLEDGMENTS}

L.W. and W. Z. prepared the manuscript. All authors reviewed the manuscript. This work was financially supported by the National Natural Science Foundation of China (31890773), Fundamental Research Funds for the Central Universities (No. 2016ZCQ01), and Beijing Forestry University Outstanding Young Talent Cultivation Project (2019JQ03004).

\section{REFERENCES CITED}

Aziz, N. A., Latip, A. F. A., Peng, L. C., Latif, N. H. A., Brosse, N., Hashim, R., and Hussin, M. H. (2019). "Reinforced lignin-phenol-glyoxal (LPG) wood adhesives from coconut husk," Int. J. Biol. Macromol. 141, 185-196. DOI: 10.1016/j.ijbiomac.2019.08.255

Bagui, S. K., and Ghosh, A. (2012). "Uses of anti-glare screen barrier in economic, financial analysis and determination of optimal debt capacity ratio for a road project," Civil Eng. 16, (7) 1104-1114. DOI: 10.1007/s12205-012-1351-9

Bai, J., Shen, H., and Dong, S. (2010). "Study on eco-utilization and treatments of highway greening waste," Procedia Environ. Sci. 2, 25-31. DOI:

10.1016/j.proenv.2010.10.005

Cherubini, E., Zanghelini, G. M., Piemonte, D., Muller, N. B., Dias, R., Kabe, Y. H. O., and Soto, J. (2019). "Environmental sustainability for highways operation: Comparative analysis of plastic and steel screen anti-glare systems," Journal of Cleaner Production 240, Article ID 118152. DOI: 10.1016/j.jclepro.2019.118152

Fernandes, L. C. (2005). "Absorptive and tinted contact lens for reduction of glare," Int. Congr. Ser. 1282, 534-538. DOI: 10.1016/j.ics.2005.05.071

Furuno, T., Imamura, Y., and Kajita, H. (2004). "The modification of wood by treatment with low molecular weight phenol-formaldehyde resin: A properties enhancement 
with neutralized phenolic-resin and resin penetration into wood cell walls," Wood Sci. Technol. 37(5), 349-361. DOI: 10.1007/s00226-003-0176-6

GB/T 2406.2. (1992). "Plastics - Determination of flammability by oxygen index," Ministry of Chemical Industry, PRC, China.

GB/T 17657. (1999). "Test methods of evaluating the properties of wood-based panels and surface decorated wood-based panels," The state forestry administration of the People's Republic of China, China.

GB/T 24718. (2009). "Anti-glare board," Traffic Engineering Facilities Highway, China

GB/T 17657. (2013). "Test methods of evaluating the properties of wood-based panels and surface decorated wood-based panels," The state forestry administration of the People's Republic of China, China.

Guan, C., Zhang, A., Zhao, B., Zhang, J., and Zhang, W. (2016). "Preparation and properties of the wood-based anti-glare plates based on high greening waste," China Forest Products Industry 43(8), 18-22. DOI: 10.19531/j.issn.1001-5299.2016.08.005

Han, D., Li, B., and Cheng, J. (2018). "Study on the design of anti-dazzle facilities under mixed traffic conditions," Xi 'an University of Arts and Sciences 11(2), 116-120. DOI: 10.3969/j.issn.1008-5564.2008.02.028

Hermawan, A., Nakahara, T., Sakagami, H., Fujimoto, N., and Uchikura, K. (2013). "Performance of Sugi lamina impregnated with low-molecular weight phenolic resin,” J. Wood Sci. 59, 299-306. DOI: 10.1007/s10086-013-1338-2

Li, R. (2014). "Quality requirements and construction supervision of antiglare board," Communications Standardization 17, 133-135. DOI: 10.16503/j.cnki.20959931.2014.17.026

Li, Y. (2010). "Stress analysis of anti-glare board for expressway under wind load," Electromechanical Product Development and Innovation 23(1), 187-192. DOI: 10.3969/j.issn.1002-6673.2010.01.075

Liang, B. (2012). "Technical requirements and use value of anti-glare board installation on Qilin,” Shanxi Architecture 38(1), 156-157. DOI: 10.3969/j.issn.10096825.2012.01.090

Shams, I., Yano, H., and Endou, K. (2004). "Compressive deformation of wood impregnated with low molecular weight phenol formaldehyde (PF) resin I: Effects of pressing pressure and pressure holding," J. Wood Sci. 50, 337-342. DOI: 10.1007/s10086-003-0570-6

Tian, X., Ji, S., and Can, Z. (2014) "Analysis on the anti-glare plate setting distance on horizontal curve sections of expressway," Appl. Mech. Mater. 587-589, 2156-2159. DOI: $10.4028 /$ www.scientific.net/AMM.587-589.2156

Tollazzi, T., and Rencelj, M. (2012). "Typical deficiencies in traffic safety and irregularities of Slovenian roads, social and behavioral sciences," KSCE J. Civ. Eng. 53, 655-663. DOI: 10.1016/j.sbspro.2012.09.915

Tu, Z., Ye, Y., and Liu, Y. (2004). "Research on technique parameter for anti-glaring board of imitated shape," Central South Highway Engineering 29(3), 132-141. DOI: 10.3969/j.issn.1674-0610.2004.03.039

Wu, X. (2012). Study on Application of Phenolic Resin Adhesive Cured Under Low Temperature to Container Floors, Master's Thesis, Nanjing Forestry University, Nanjing, China.

Yi, Z., Li, C., Li, J., Zhang, W., and Li, J. (2016). "Production and applications of antiglare plate used on highway," China Wood-based Panels 23(2), 5-7. DOI: 10.3969/j.issn.1673-5064.2016.02.002 
Yu, Z., Chang, S., Hu, J., Tan, Y., Shang, J., Xu, D., and Liu, Y. (2019). "Study on the main physical and mechanical properties of Tilia sp. used for shutters," Journal of Forestry Engineering 4(3), 159-157. DOI: 10.13360/j.issn.2096-1359.2019.03.024

Zhang, J. (2008). "Principles and application of highway "anti-glare" measures," Highway Transportation in Inner Mongolia 2, 59-61. DOI: 10.3969/j.issn.10050574.2008.02.025

Article submitted: October 24, 2020; Peer review completed: December 21, 2020;

Revised version received and accepted: January 9, 2021; Published: January 13, 2021. DOI: 10.15376/biores.16.1.1561-1580 